\title{
Study on the effect of intracoronary Adenosine on the incidence of myonecrosis after elective percutaneous coronary intervention
}

\author{
Md. Razib Ahsan1, Md. Abu Siddique1, K.M.H.S. Sirajul Haque1, Syed Ali Ahsan¹, \\ Md. Khurshed Ahmed ${ }^{1}$ and Md. Mukhlesur Rahman. ${ }^{1}$ \\ ${ }^{1}$ Department of Cardiology, Bangabandhu Sheikh Mujib Medical University, Shahbag, Dhaka. \\ Address for correspondence \\ Dr. Md. Razib Ahsan, Department of Cardiology, Bangabandhu Sheikh Mujib Medical University, Shahbag, Dhaka. \\ E-mail : dr_razib@yahoo.com
}

\begin{abstract}
Appearance of serum creatine kinase MB fraction (CK-MB), reflecting the periprocedural myonecrosis, after successful percutaneous coronary intervention (PCI) is associated with future cardiac adverse events. The intracoronary adenosine on the incidence of myonecrosis after elective PCI was assessed. In this prospective, case control study with a total of 60 patients, 30 cases pretreated with 50 micro grams bolus intracoronary adenosine before advancement of guidewire and 30 controls not pretreated was studied during elective PCI. Both groups received statin and loading dose of Clopidogrel. Myonecrosis was assessed by CK-MB level after PCI. Post procedural myonecrosis occurred in $16.7 \%(\mathrm{n}=5)$ in case group and $36.7 \%$ $(\mathrm{n}=11)$ in control group $(\mathrm{OR}=1.818 ; 95 \%$ CI $0.841 ; \mathrm{P}=0.080)$. The result is not statistically significant but shows that the incidence of myonecrosis was reduced from $36.7 \%$ to $16.7 \%$. Intracoronary adenosine reduces the incidence of myonecrosis after elective PCI.
\end{abstract}

\section{Keywords}

Adenosine; Creatine kinase MB fraction; Intracoronary; Myonecrosis; Percutaneous coronary intervention; Periprocedural.

\section{Introduction}

Percutaneous coronary intervention (PCI) has been established as an effective treatment strategy for obstructive coronary artery disease. PCI is associated with 5\% to $30 \%$ incidence of elevation of serum creatine kinase MB fraction (CK-MB), reflecting the periprocedural myonecrosis . ${ }^{1}$ Appearance of CK-MB in the circulation is the strongest predictor of long term clinical outcome of PCI, 2,3,4,5 correlating the deleterious consequences of myonecrosis on left ventricular function or electrophysiological stability. ${ }^{6}$ Pathophysiology of myonecrosis during PCI has been related to abrupt closure of the vessel, side branch occlusion, major intimal dissection, intramural thrombus formation, coronary spasm or distal athero-emolization. ${ }^{1,} 7$ The first five causes may be clinically apparent and measures can be taken during the procedure, the latter may be entirely asymptomatic and occurs even angiographically uneventful procedure. CK-MB elevation after PCI may be consequence of micro infarction due to distal embolization of atherogenic materials from catheter based disruption of atherosclerotic plaque .7, 8,9

Adenosine is a naturally occurring nucleoside with a half life in blood of less than 10 second. Intracoronary adenosine administration is feasible and adjunct to primary PCI is well tolerated and ameliorates flow, prevents no reflow phenomenon, improves left ventricular function and associated with more favorable clinical course .10,11,12 Studies show pretreatment with intracoronary adenosine infusion reduces the CK-MB elevation after non urgent PCI .13, 14 The mechanisms of the cardioprotective effect of adenosine include preconditioning, ${ }^{15}$ antiplatelet activity, ${ }^{16}$ anti inflammatory effect ${ }^{17}$ and hyperaemia .18 There is evidence from previous study that despite a short serum half life, the cardio-protective effect of intracoronary adenosine infusion in human subjects persisting much longer. 15

In this prospective, case control study, we wanted to show that adenosine induced hyperaemia can reduce the deleterious effect of distal embolization associated with elective PCI through dilatation of microvasculature. This may decrease capillary obstruction by facilitating the passage of embolized thrombi throughout the microvasculature to the venous end of coronary circulation, there by reducing the post procedural micro infarction and myonecrosis.

\section{Materials and methods Study population}

This prospective, case control study was performed consequently on the patients who were scheduled to undergo elective PCI, at the Department of Cardiology, Bangabandhu Sheikh Mujib Medical University, Dhaka, 
during the period of February 2007 to September 2007, considering the inclusion and exclusion criteria. Inclusion criteria were age between 30 and 75 years, base line - MB level within normal limit, stable or unstable angina, and angiographic lesion ? 70\% in diameter. Exclusion criteria were complete occlusion of vessel (TIMI grade-0), thrombus laden lesion, significant left main disease, left ventricular ejection fraction $<30 \%$, bradycardia (heart rate $<50$ bpm), myocardial Infarction (MI) within one week, known case of COPD or Bronchial Asthma, patient taking theophylline preparation. The ethics committee of the Department of Cardiology, BSMMU, approved the study protocol. All patients were informed about the necessity, risk and benefit of intracoronary Adenosine administration. Informed written consent was taken from each patient.

\section{Study protocol}

Case group received 50 micro grams of adenosine (diluted into $5 \mathrm{ml}$ normal saline) through the guiding catheter into the target coronary artery prior to guidewire advancement. For multivessel stenting, another 50 micro grams of adenosine was given prior to intervention of the subsequent vessel. Control group did not receive adenosine pretreatment. Both groups Pretreatment with statin (Atrovastatin 20 $\mathrm{mg} /$ day) for 3 days 19 and $300 \mathrm{mg}$ loading dose of Clopidogrel in both groups at least 6 hour before the procedure.$^{20}$ The rest of the intervention procedure was carried out in usual manner in both groups. Following the procedure, blood sample was collected after 12 to 24 hour following intervention to measure the serum CK-MB level.

\section{Evaluation of test result}

After collecting the blood from the patient, serum was separated by centrifugation and within 6 hours test was done.
Post PCI creatine kinase MB fraction (CK-MB) levels were considered abnormal if they were elevated above the upper limit of normal. This was set at 25 IU/L by the laboratory of our Clinical Pathology Department. Primary endpoint of this study was to evaluate any elevation of CK-MB above $25 \mathrm{IU} / \mathrm{L}$ (incidence of myonecrosis), in patients undergoing elective PCI with or without pretreatment with intracoronary adenosine. If the first blood sample showed a CK-MB level > 2 times upper normal limit (> $50 \mathrm{IU} / \mathrm{L})$, a second blood sample would be drawn every 8 hour later until a descending trend was observed. For patients with two or more blood samples drawn, the peak CK-MB was used for analysis. Secondary endpoint was the post-procedural non Q wave myocardial infarction. This was defined by post-procedural increase of CK-MB more than 3 times above the upper limit of normal .1,9

\section{Statistical analysis}

Data were expressed as mean \pm SD (standard deviation). Continuous variables were analyzed by unpaired student's $t$ test. Categorical variables were analyzed by Chi-Square Test $\left(x^{2}\right.$ test). Possible confounders of our study were multi-vessel stenting and stent length. As a weakest confounder we excluded stent length and quantile regression was used to adjust for the effects of multi-vessel stenting, All probability values were two tailed and $\mathrm{P}<0.05$ were considered significant. Data were analyzed with computer-based software, Statistical Package for Social Science (SPSS).

\section{Results}

A total of 60 patients, 30 cases pretreated with intracoronary adenosine and 30 controls not pretreated, during elec-

Table I : Clinical, angiographic and procedural characteristics of the study subjects

\begin{tabular}{|c|c|c|c|c|c|}
\hline Parameters & Case $(n=30)$ & Percent & Control $(n=30)$ & Percent & $P$ value \\
\hline Mean Age in years (SD) & $52.70 \pm 9.23$ & - & 51.27 & $(10.98)$ & 0.586 \\
\hline Male sex (n, \%) & 27 & $(90.0)$ & 27 & $(90.0)$ & 1.000 \\
\hline $\mathrm{BMI}$ in $\mathrm{kg} / \mathrm{m}^{2}(\mathrm{SD})$ & $24.47 \pm 2.79$ & - & $24.77 \pm 2.42$ & & 0.661 \\
\hline Hypertension (n, \%) & 16 & $(53.3)$ & 19 & $(63.3)$ & 0.432 \\
\hline Smoking habit (n, \%) & 20 & $(66.7)$ & 20 & $(66.7)$ & 1.000 \\
\hline Diabetes $(n, \%)$ & 13 & $(43.3)$ & 11 & $(36.7)$ & 0.598 \\
\hline Dyslipidemia(n, \%) & 10 & (33.3) & 12 & $(40.0)$ & 0.592 \\
\hline Sedentary lifestyle (n, \%) & 10 & (33.3) & 15 & $(50.0)$ & 0.190 \\
\hline Positive Family history (n, \%) & 13 & $(43.3)$ & 13 & (43.3) & 1.00 \\
\hline Type of angina (n, \%) & & & & & 0.347 \\
\hline Stable & 22 & $(73.3)$ & 25 & $(83.3)$ & \\
\hline Unstable & 8 & (26.7) & 5 & (16.7) & \\
\hline Previous MI (n, \%) & 6 & $(20.0)$ & 5 & $(16.7)$ & 0.739 \\
\hline Vessel involved & 32 & 32 & & & 0.484 \\
\hline LAD (n, \%) & 18 & $(56.3)$ & 16 & $(50.0)$ & \\
\hline $\operatorname{LCX}(n, \%)$ & 4 & $(12.5)$ & 2 & $(6.3)$ & \\
\hline $\operatorname{RCA}(n, \%)$ & 10 & (31.3) & 14 & $(43.8)$ & \\
\hline Lesion site & 32 & & 32 & & 0.553 \\
\hline Proximal (n, \%) & 8 & $(25.0)$ & 12 & $(37.5)$ & \\
\hline Middle (n, \%) & 20 & $(62.5)$ & 17 & $(53.1)$ & \\
\hline Distal (n, \%) & 4 & (12.5) & 3 & $(9.4)$ & \\
\hline
\end{tabular}




\begin{tabular}{|c|c|c|c|c|c|}
\hline Parameters & Case $(n=30)$ & Percent & Control $(n=30)$ & Percent & P value \\
\hline Angulated lesion, >45 degree (n, \%) & 3 & (9.4) & 3 & $(9.4)$ & 1.000 \\
\hline Proximal tortousity $(\mathrm{n}, \%$ & 2 & $(6.2)$ & 4 & $(12.5)$ & 0.129 \\
\hline Bifurcation lesion $(\mathrm{n}, \%)$ & 3 & (9.4) & 1 & $(3.1)$ & 0.601 \\
\hline Side branch compromised, TIMI flow $<3$ (n, \%) & 2 & $(6.2)$ & 1 & $(3.1)$ & 0.854 \\
\hline Type A (n, \%) & 15 & $(50.0)$ & 13 & $(40.8)$ & \\
\hline Type $B_{1}(n, \%)$ & 13 & $(40.6)$ & 13 & $(40.6)$ & \\
\hline Type $B_{2}(n, \%)$ & 3 & $(9.4)$ & 4 & $(12.5)$ & \\
\hline Type C (n, \%) & 1 & (3.1) & 2 & $(6.3)$ & \\
\hline Vessel involvement & & & & & 1.000 \\
\hline Single-vessel (n, \%) & 28 & (93.3) & 28 & (93.3) & \\
\hline Double-vessel (n, \%) & 2 & $(6.7)$ & 2 & $(6.7)$ & \\
\hline Number of stents used & & & & & 1.000 \\
\hline One $(\mathrm{n}, \%)$ & 28 & (93.3) & 28 & $(93.3)$ & \\
\hline Two $(\mathrm{n}, \%)$ & 2 & $(6.7)$ & 2 & $(6.7)$ & \\
\hline \multicolumn{6}{|l|}{ Baseline TIMI flow } \\
\hline Grade I & 2 & $(6.3)$ & 2 & $(6.3)$ & \\
\hline Grade II & 3 & $(9.4)$ & 1 & $(3.1)$ & \\
\hline Grade III & 27 & $(84.4)$ & 29 & $(90.6)$ & \\
\hline \multicolumn{6}{|l|}{ Final TIMI flow } \\
\hline Grade III & 32 & $(100.0)$ & 32 & $(100.0)$ & \\
\hline Lesion length, mm (SD) & $10.18 \pm 3.72$ & - & $10.91 \pm 4.48$ & - & 0.479 \\
\hline Stent length, mm (SD) & $19.09 \pm 11.70$ & - & $17.84 \pm 4.86$ & - & 0.579 \\
\hline Baseline CK-MB, IU/L (SD) & $14.30 \pm 3.60$ & - & $14.47 \pm 2.94$ & - & 0.986 \\
\hline After procedure peak CK-MB, IU/L (SD) & $28.80 \pm 16.87$ & - & $36.62 \pm 19.84$ & - & 0.106 \\
\hline
\end{tabular}

TIMI $=$ Thrombolysis in myocardial infarction, $\mathrm{p}$ value $<0.05$ is significant

tive PCI were included in this study. Data obtained from both case and control groups were reviewed and analyzed. The majority $90 \%(n=27)$ patients of both case and control groups were male. $10 \%(n-3)$ patients in both groups were female.

The baseline clinical, angiographic, and procedural characteristics of the patients were similar in the two groups. After adenosine administration, no patient developed significant bradycardia or heart block requiring pacing. None of the patients in this study received glycoprotein IIb/IIIa inhibitors. All procedures were successful and uncomplicated. Slow-flow or no-reflow phenomenon did not occur in any study subject. There was significant procedural improvement after PCI in both case and control groups.

Double vessel stenting were done in $6.7 \%(n=2)$ patients in both group with two stents in separate vessels. No drug eluting stent was implanted in our study subjects. Mean Stent length $(\mathrm{mm})$ was $19.09 \pm 11.70$ and $17.84 \pm 4.86$ in study group and control group, respectively. Baseline mean CK-MB level in case was $14.30 \pm 3.60 \mathrm{IU} / \mathrm{L}$ and control was $14.47 \pm 2.94 \mathrm{IU} / \mathrm{L}$. Post procedural mean CK-MB level in case was $28.80 \pm 16.87 \mathrm{IU} / \mathrm{L}$ and control was 36.62 $\pm 19.84 \mathrm{IU} / \mathrm{L}$.

Post procedural CK-MB level was within normal limit in $83.3 \%(n=25)$ in case and $63.3 \%(n=19)$ in control. CKMB level was > $25 \mathrm{IU} / \mathrm{L}$ in $6.7 \%(\mathrm{n}=2)$ and $13.3 \%(\mathrm{n}=4)$ patients in case group and control group, respectively. CKMB level was 2 times of upper limit ( $>2$ X 25 IU/L) in case was $6.7 \%(n=2)$ and control was $10.0 \%(n=3)$. The incidence of post procedural non $\mathrm{Q}$ wave myocardial infarction (CK-MB level was > 3 X $25 \mathrm{IU} / \mathrm{L}$ ) were $3.3 \%$ $(n=1)$ and $13.3 \%(n=4)$ in case group and control group, respectively. Post procedural CK-MB level was considerably elevated in control group.

Myonecrosis occurred more frequently in control group $(36.7 \%$; $n=11)$, who did not receive intracoronary adenosine than case group $(16.7 \% ; n=5)$, who received intracoronary adenosine during elective PCI $(\mathrm{OR}=1.818 ; 95 \% \mathrm{CI}$ $0.841 ; \mathrm{P}=0.080)$.

Table II : Distribution of post procedural CKMB level

\begin{tabular}{lllll}
\hline CK-MB (IU/L) & \multicolumn{2}{c}{ Case } & \multicolumn{2}{c}{ Control } \\
& No. $(\%)$ & No. & $(\%)$ \\
\hline Within upper limit of normal (ULN) & 25 & $(83.3)$ & 19 & $(63.3)$ \\
Above upper limit of normal (ULN) & 5 & $(16.7)$ & 11 & $(36.7)$ \\
More than one times of ULN & 2 & $(6.7)$ & 4 & $(13.3)$ \\
More than two times of ULN & 2 & $(6.7)$ & 3 & $(10.0)$ \\
\hline
\end{tabular}

Table III : Odd ratio estimates of myonecrosis for the effect of adenosine treatment, multivessel stenting and type of angina

\begin{tabular}{lllllll}
\hline Parameters & \multicolumn{3}{l}{ Myonecrosis } & \multicolumn{2}{l}{ No myonecrosis } & Odds \\
& No. & $(\%)$ & No. & $(\%)$ & P value & ratio \\
\hline $\begin{array}{l}\text { Study group } \\
\quad \text { Case }\end{array}$ & 5 & $(16.7)$ & 25 & $(83.3)$ & 0.080 & 1.818 \\
$\quad$ Control & 11 & $(36.7)$ & 19 & $(63.3)$ & & \\
$\begin{array}{l}\text { Multi-vessel stenting } \\
\quad \text { Yes }\end{array}$ & 1 & $(25.0)$ & 3 & $(75.0)$ & 0.938 & 1.091 \\
$\quad$ No & 15 & $(26.8)$ & 41 & $(73.2)$ & & \\
$\begin{array}{l}\text { Type of angina } \\
\text { Stable }\end{array}$ & 12 & $(25.5)$ & 35 & $(74.5)$ & 0.705 & 1.061 \\
$\quad$ Unstable & 4 & $(30.8)$ & 9 & $(69.2)$ & & \\
\hline
\end{tabular}

$\mathrm{p}$ value $<0.05$ is significant 


\section{Discussion}

There are few trials investigating the impact of intracoronary adenosine pretreatment on the incidence of myonecrosis after non-urgent PCI. We found that pretreatment with 50 micro grams of adenosine decreases the incidence of myonecrosis after PCI.

Appearance of serum CK-MB, reflecting the periprocedural myonecrosis, after successful PCI, is associated with future cardiac adverse events. ${ }^{2,3,4,6,21} \mathrm{~A}$ possible aetiology of myonecrosis after PCI might be distal embolization of atherogenic materials from plaque disruption, ${ }^{7}$ causing obstruction of blood flow at capillary level resulting in micro-infarction. 8,9 Recently several studies show that pretreatment with statins ${ }^{19}, 22$ and loading dose of clopidogrel20, 23, 24 before the elective PCI is able to reduce procedure related myonecrosis.

Adenosine is a potent coronary vasodilator act through $\mathrm{A}_{2 \mathrm{a}}$ receptor and increase cyclic AMP causes maximal decrease of coronary resistance. Hyperaemic effect of adenosine may be beneficial to ameliorate distal embolization of platelet thrombi following elective PCI. One animal study suggested that endogenous release of adenosine could compensate distal embolization of small particles through hyperaemic effect of adenosine. ${ }^{25}$ The minimum dose of adenosine required to achieve minimum fractional flow reserve (or maximum hyperaemia) is 42 micrograms for both left and right coronary artery in human without any significant side effect. 26 Although only fraction of the administered adenosine would reach the target distal lesion, 50 micro grams intracoronary adenosine was sufficient to achieve maximum hyperaemia. ${ }^{14}$

We used bolus doses of adenosine at 50 micro grams, administered through the guiding catheter before PCI to each lesion. Moreover, an intracoronary bolus approach has advantage of ease of administration, lower cost and reduced risk of bradycardia.

Recently a study was done by Lee et al. 2007, involving total of 62 patients (adenosine group, $\mathrm{n}=31$; standard group, $\mathrm{n}=31$ ), had more or less similar inclusion, exclusion criteria and study method compared with our study. In our study post procedural myonecrosis occurred in $16.7 \%$ $(n=5)$ in case group and $36.7 \%(n=11)$ in control group $(\mathrm{OR}=1.818 ; 95 \%$ CI $0.841 ; \mathrm{P}=0.080)$. The study of Lee et al. 2007, showed that Post PCI myonecrosis occurred more frequently in the standard $(39 \%, \mathrm{n}=12)$ than in the adenosine group $(13 \%, \mathrm{n}=4) .{ }^{14}$ In the ADELINE pilot trial, involving 28 patients, a rise in CK-MB level occurred in 2 of the 12 patients in adenosine treated group and 8 of the 16 patients in the control group, showed that pretreatment with intracoronary adenosine infusion reduced the postprocedural CK-MB elevation after non-urgent PCI .13

Our result is not statistically significant. These may be due to small sample size. But shows that the incidence of myonecrosis was reduced from $36.7 \%$ to $16.7 \%$ who pretreated with intracoronary adenosine before guide wire advancement in elective PCI. This result is almost consistent with the study of Lee $\mathrm{CH}$ et al. 2007, which showed that the incidence of myonecrosis was reduced from $39 \%$ to $13 \%$, with adenosine pretreatment during elective PCI.

\section{Conclusion}

From the above data we can come to a conclusion that bolus administration of intracoronary adenosine through the guiding catheter before advancement of guidewire is feasible, safe, efficacious and cost effective during elective PCI. Adenosine induced hyperaemic effect reduces the incidence of myonecrosis during elective PCI. The result of our study supports the routine use of intracoronary adenosine during elective PCI which would be a new horizon in the field of interventional cardiology and need for further investigation in larger trial.

\section{Limitations}

This study was done in small scale, which may lead to inadequate power to detect a statistically significant difference between two groups. In this study consecutive sample was taken and randomization was not feasible. Inter-operator variations were not taken into account. Number of female patient was less. Short or long term outcome was not evaluated. Study population was South Asian in origin. The result of the study may thus not be applicable to broader large ethnic groups. Post-PCI troponin level was not measured, but its prognostic significance in this setting remaining controversial. $21,27,28,29$

\section{References}

1. Califf RM, Abdelmeguid AE, Kuntz RE, Popma JJ, Davidson CJ, Cohen EA, Kleiman NS, Mahaffey KW, Topol EJ, Pepine CJ, Lipicky RJ, Granger CB, Harrington RA, Tardiff BE, Crenshaw BS, Bauman RP, Zuckerman BD, Chaitman BR, Bittl JA, Ohman EM. Myonecrosis after revascularization procedures. J Am Coll Cardiol 1998; $31: 241-51$

2. Abdelmeguid AE, Topol EJ, Whitlow PL, Sapp SK, Ellis SG. Significance of mild transient release of creatine kinaseMB fraction after percutaneous coronary intervention. Circulation 1996; 94: 1528- 36.

3. Brener SJ, Ellis SG, Schnerider J, Topol EJ. Frequency and long-term impact of myonecrosis after coronary stenting. Eur Heart J 2002; 23: 869-76.

4. Ioannidis JP, Karvouni E, Katritsis DG. Mortality risk conferred by small elevations of creatine kinase-MB isoenzyme after percutaneous coronary intervention. J Am Coll Cardiol 2003; 42: 1406-11.

5. Kini AS ,Lee P,Marmur JD, Agarwal A, Duffy ME, Kim MC, Sharma SK. Correlation of postpercutaneous coronary intervention creatine kinase-MB and troponin I elevation in predicting med-term mortality. Am J Cardiol 2004; 93: 1823 . 
6. Ellis SG, Chew D, Chan A, Withlow PL, Schneider JP, Topol EJ. Death following Creatine kinase- MB elevation after coronary intervention: Identification of an early risk period: Importance of creatine kinase- MB level, completeness of revascularization, ventricular function and probable benefit of statin therapy. Circulation 2002; 106: 1205-10.

7. Mehran R, Dangas G, Mintz GS, Lansky AJ, Pichard AD, Satler LF, Kent KM, Stone GW, Leon MB. Atherosclerotic plaque burden and CK- MB enzyme elevation after coronary intervention: Intravascular ultrasound study of 2256 patients. Circulation 2000; 101: 604-10.

8. Choi JW, Gibson CM, Murphy SA, Davidson CJ, Kim RJ, Ricciardi MJ. Myonecrosis following stent placement: association between impaired TIMI myocardial perfusion grade and MRI visualization of microinfarction. Catheter Cardiovasc Interv 2004; 61: 472-76.

9. Ricciardi MJ, Wu E, Davidson CJ, Choi KM, Klocke FJ, Bonow RO, Judd RM, Kim RJ. Visualization of discrete microinfarction after percutaneous coronary intervention associated with mild creatine kinase- MB elevation. Circulation 2001; 103: 2780-83.

10. Claeys MJ, Bosmans J, De Ceuninck M, Beunis A, Vargauwen W, Vorlat A, Vrints CJ. Effect of intracoronary adenosine infusion during coronary intervention on myocardial reperfusion injury in patients with acute myocardial infarction. Am J Cardiol 2004; 94(1): 9-13.

11. Marzilli M, Orsini E, Maraccini P, Testa R. Beneficial effects of intracoronary adenosine as an adjunct to primary angioplasty in acute myocardial infarction. Circulation 2000; 101: 2154-59.

12. Reffelmann T, Kloner RA. The 'no-reflow' phenomenon: basic science and clinical correlates. Heart 2002; 87:162-68.

13. Desmet WJ, Dens J, Coussement P, Van de Werf F. Does adenosine prevent myocardial micronecrosis following percutaneous coronar for $\mathrm{s}$ for serum CK-MB level erum CKMB level y intervention? The ADELINE pilot trial ADEnosine LImit myocardial NEcrosis. Heart 2002; 88:293-95.

14. Lee CH, Low A, Tai BC, Co M, Chan My, Lim J, Lim YT, Tan HC. Pretreatment with Intracoronary adenosine reduces the incidence of myonecrosis after non-urgent percutaneous Intervention: a prospective randomized study. Eur Heart J 2007; 28: 19-25.

15. Leesar MA, Stoddard M, Ahmed M, Broadbent J, Bolli R. Preconditioning of human myocardium with adenosine during coronary angioplasty. Circulation 1997; 95: 2500-07.

16. Hata K, Whittaker P, Kloner RA, Pazyklenk K. Brief antecedent ischemia attenuates platelet- mediated thrombosis in damaged and stenotic canine coronary arteries: role of adenosine. Circulation 1998; 97:692-702.

17. Headrick JP, Hack B, Ashton KJ. Acute adenosinergic cardioprotection in ischaemic-reperfused hearts. Am J Physiol Heart Circ Physiol. 2003; 285: 1797- 1818.

18. Wilson RF, Wyche K, Christensen BV, Zimmer S, Laxson DD. Effects of Adenosine on human coronary arterial circulation. Circulation 1990; 82: 1995- 1606.

19. Briguori C, Colombo A, Airoldi F, Violante A, Focaccio A, Balestrieri P, Paolo Elia P, Golia B, Lepore S, Riviezzo G,
Scarpato P, Librera M, Bonozzoni E, Ricciardelli B. Statin administration before percutaneous Coronary intervention: impact on periprocedural myocardial infarction. Eur Heart J 2004; 25:1822-28.

20. Steinhubl SR, Berger PB, Mann JT 3 rd, Fry ET, DeLago, A Wilmer C, Topol EJ, CREDO Investigators. Clopidogrel for the Reduction of Events During Observation. Early and sustained dual oral antiplatelet therapy following percutaneous coronary intervention: a randomized controlled trail. JAMA 2002; 288: 2411-20.

21. Cavallini C, Savonitto S, Violini R, Arraiz G, Plebani M, Olivari Z, Rubartelli P, Battaglia S, Niccoli L, Steffenino G, Ardissino D. Italian 'Atherrosclerosis, Thorombosis Vasscular Biology' and 'Society for Invasive CardiologyGISE' Investigators. Impact of the elevation of biochemical markers of myocardial damage on long-term mortality after percutaneous coronary intervention: results of the CK-MB and PCI study. Eur Heart J 2005; 26: 1494-98.

22. Pasceri V, Patti G, Nusca A, Pristipino C, Richichi G, Sciascio DG. ARMYDA Investigators. Randomized trial of atorvastatin for reduction of myocardial damage during coronary intervention: Results from the ARMYDA (Atorvastatain for Reduction of MYocardial Damage during Angioplasty) Study. Circulation 2004; 110: 674-78.

23. Hochhozer W, Trenk D, Frundi D, Blanke P, Fischer B, Andris K, Bestehorn HP, Buttner HJ, Newmann FJ. Time dependence of platelet inhibition after a 600-mg loading dose of clopidogrel in a large, unselected cohort of candidates for percutaneous coronary intervention. Circulation 2005; 111: 2560-64.

24. Patti G, Colonna G, Pasceri V, Pepe LL, Montinaro A, Sciascio DG. Randomized trial of high loading dose of clopidogrel for reduction of periprocedural myocardial infarction in patients undergoing coronary intervention: Results from the ARMYDA-2 (Antiplatelet therapy for Reduction of MYocardial Damage during Angioplasty) study. Circulation 2005; 111: 2099-2106.

25. Hori M, Inoue M, Kitakaze M, Koretsune Y, Iwai K, Tamai J, Ito H, Kitabatake A, sato T, Kamada T. Role of Adenosine in hyperemic response of coronary blood flow in microembolization. Am J Physiol 1986; 250: 509-18.

26. Murtagh B, Higano S, Lennon R, Mathew V, Holmes DR $\mathrm{Jr}$, Lerman A. Role of incremental doses of intracoronary adenosine for fractional flow reserve assessment. Am Heart J 2003; 146 (1): 99-105.

27. Kizer JR, Muttrej MR, Matthai WH, McConnell J, Nardone $\mathrm{H}$, Sonel AF, Keane MG, Wilensky RL. Role of cardiac troponin $\mathrm{T}$ in the long-term risk stratification of patients undergoing percutaneous coronary intervention. Eur Heart J 2003; 24: 1314-22.

28. Natarajan MK, Kreatsoulas C, Velianou JL, Mehta SR, Pericak D, Goodhart DM. Incidence,predictors, and clinical significance of troponin-I elevation without creatine kinase elevation following percuataneous coronary interventions. Am J Cardiol 2004; 93: 750-53.

29. Silber S, Aibertsson P, Aviles FF,Camici PG, Clombo A,Hamm C ,Jorgensen J, Marco J, Nordrehaug J, Ruzyllo W, Urban P, Stone GW, Wijins W. Guidelines for Percutaneous Coronary Interventions. Eur Heart J, March 29, 2005. 